\title{
HUBUNGAN DURASI RATA-RATA PENGGUNAAN SMARTPHONE DENGAN KEJADIAN TENOSYNOVITIS DE QUERVAIN
}

\section{Sayyid Muhammad Sahil Haikal'1), Yetty Octavia Hutahaean²), dan Muhammad Khairul Nuryanto ${ }^{3)}$}

\author{
${ }^{1}$ Program Studi Kedokteran, Fakultas Kedokteran, Universitas Mulawarman; \\ 2Laboratorium IImu Penyakit Saraf, Fakultas Kedokteran, Universitas Mulawarman; \\ ${ }^{3}$ Laboratorium IImu Kesehatan Masyarakat, Fakultas Kedokteran, Universitas \\ Mulawarman \\ Email: akrizky47@gmail.com
}

\begin{abstract}
Background. Smartphone is one of the most commonly used communication device compared to various other devices both in young and old generation. Excessive use of smartphones can cause health problems, one of them is Tenosynovitis De Quervain (TDQ).

Purpose. An understanding of the relationship between the average duration of smartphone usage per day with $T D Q$ incidence.

Methods. This research is an analytic observational with cross sectional approach. The research samples were 153 students of the Medical Study Program at the Faculty of Medicine, Mulawarman University, taken using consecutive sampling technique. The data was analyzed using chi-square statistical test.

Results. $86 \%$ of Mulawarman University Faculty of Medicine students use smartphones with a duration of $\geq 5$ hours. $68 \%$ of Mulawarman University Faculty of Medicine students have positive $T D Q$ results. The relationship of the average duration of smartphone use with TDQ events showed $p=0,000$.
\end{abstract}

Conclusion. There is a relationship between the average duration of smartphone usage with TDQ incidence.

Keywords : Usage duration, smartphone, tenosynovitis, de quervain

\begin{abstract}
Abstrak
Latar Belakang. Smartphone merupakan salah satu alat komunikasi yang paling sering digunakan dibanding alat komunikasi lainnya baik oleh kalangan muda maupun kalangan tua. Penggunaan smartphone yang berlebihan dapat menyebabkan gangguan kesehatan salah satunya ialah Tenosynovitis De Quervain (TDQ).

Tujuan. Mengetahui hubungan durasi rata-rata penggunaan smartphone perhari dengan kejadian TDQ.

Metode. Penelitian ini merupakan observasional analitik dengan pendekatan cross sectional. Sampel penelitian adalah mahasiswa Program Studi Kedokteran Fakultas Kedokteran Universitas Mulawarman sebanyak 153 responden yang diambil secara consecutive sampling. Data dianalisis dengan menggunakan uji statistik chi-square.
\end{abstract}


Hasil. $86 \%$ mahasiswa Fakultas Kedokteran Universitas Mulawarman menggunakan smartphone dengan durasi $\geq 5$ jam. 68\% mahasiswa Fakultas Kedokteran Universitas Mulawarman memiliki hasil TDQ positif. Hubungan durasi rata-rata penggunaan smartphone dengan kejadian TDQ menunjukkan $p=0,000$.

Kesimpulan. Terdapat hubungan antara durasi rata-rata penggunaan smartphone dengan kejadian TDQ.

Kata Kunci: durasi penggunaan, smartphone, tenosynovitis, de quervain

\section{PENDAHULUAN}

Gadget adalah alat elektronik yang mudah di bawa kemana saja untuk keperluan komunikasi maupun mengakses informasi. Zaman sekarang, gadget sudah lebih berkembang. Awalnya gadget hanya dapat melakukan komunikasi tetapi sekarang sudah dapat melakukan banyak hal sehingga gadget digunakan oleh banyak orang, baik kalangan tua maupun kalangan muda (Nurmalasari \& Wulandari, 2018) Salah satu jenis gadget ialah smartphone. Dalam berberapa tahun terakhir, smartphone telah menunjukan pertumbuhan yang luar biasa dengan perkiraan pengiriman global tahunan mencapai 1,42 milliar unit pada 2018. Tak heran jika dikatakan smartphone sebagai jenis gadget yang paling akrab dengan kehidupan manusia sehari-hari (Lee, 2016). Indonesia merupakan pengguna smartphone tertinggi di Asia Tenggara (Oktario, 2017). Kemenkominfo RI, mengatakan bahwa Indonesia akan menjadi negara dengan pengguna aktif smartphone terbesar keempat di dunia setelah Cina, India dan Amerika Serikat (Kemenkominfo RI, 2015).

Smartphone memiliki dampak negatif terutama dalam kesehatan. Saat menggunakan smartphone akan ada penggunaan ibu jari yang berlebihan. Penggunaan ibu jari yang berlebihan tersebut dapat mempermudah terjadinya nyeri pada ibu jari (Nisa, Umer , \& Hassan, 2016). Kondisi tersebut dapat memicu terjadinya peradangan pada pelapis tendon kompartemen dorsal pertama pergelangan tangan (Hingarajia, Patel, Desai, \& Dora, 2018). Peradangan tersebut dapat menyebabkan gejala berupa nyeri pada jari (Kulkarni \& Babhulkar, 2016).

Salah satu gangguan akibat penggunaan ibu jari yang berlebihan adalah Tenosynovitis De Quervain (TDQ). TDQ merupakan suatu kondisi tendovaginitis stenosis pada kompartemen dorsal pertama dari pergelangan tangan. Tendovaginitis ialah suatu inflamasi dari pembungkus tendon yang menjadi karakteristik dari TDQ (Helmi, 2015). TDQ merupakan penyakit yang cukup sering terjadi. TDQ sering ditemukan pada individu yang bekerja dengan menggunakan gerakan tangan secara berulang dan terus menerus. Penyakit ini tidak menyebabkan kematian namun 
menimbulkan keluhan berupa rasa nyeri progresif dan keterbatasan dalam bergerak pada pergelangan tangan (Ali, Asim, Danish, Ahmad, Iqbal, \& Hassan, 2014). Penderita mengalami nyeri, terutama pada gerakan otot Ekstensor Pollicis Brevis (EPB) dan Abduktor Pollicis Longus (APL), yaitu bila menggerakan ibu jari (Sjamsuhidajat \& de Jong, 2017). Penelitian yang dilakukan oleh Sehar, Ashraf, Rasool \& Raza, ditemukan 47 (40\%) dari 110 total responden usia 16-30 tahun yang menggunakan smartphone mengalami nyeri pada ibu jari. Berdasarkan durasi penggunaan, ditemukan 45 responden dari total 110 responden menggunakan smartphone dengan durasi perhari 5-7 jam (Sehar, Ashraf, Rasool, \& Raza, 2018).

\section{METODE PENELITIAN}

Penelitian ini merupakan jenis penelitian observasional analitik dengan pendekatan cross sectional pada mahasiswa Fakultas Kedokteran Universitas Mulawarman yang terdiri dari 3 angkatan sejak bulan Mei sampai dengan bulan Juni 2019. Kriteria inklusi pada penelitian ini adalah 1) Mahasiswa aktif program studi kedokteran Fakultas Kedokteran UNMUL 2) Menggunakan smartphone setiap hari 3) Bersedia menjadi responden. Adapun yang menjadi kriteria eksklusi ialah 1) Ada riwayat cedera tangan dalam kurun waktu 2 minggu terakhir 2) Ada riwayat diabetes mellitus, rheumatoid arthritis, osteoarthritis dan gout arthritis 3) Ada riwayat deformitas dan perubahan bentuk sendi jari 4) Ada riwayat operasi pada daerah pergelangan tangan dan ibu jari 5) Melakukan aktivitas olahraga bulutangkis, tenis, mendayung, golf, voli dan boling setiap hari 6) Menggunakan game konsol setiap hari.

Sampel terdiri dari 153 orang yang diperoleh berdasarkan data primer yang dikumpulkan oleh peneliti melalui pengisian kuesioner. Kueisioner yang digunakan untuk menilai durasi rata-rata penggunaan smartphone adalah kuesioner yang dibuat oleh peneliti sedangkan variabel TDQ diukur menggunakan pemeriksaan fisik finkelstein test yang dilakukan oleh peneliti. Pengolahan data dilakukan dengan menggunakan software Microsoft Word 2016, Microsoft Excel 2016, IBM SPSS 23. Analisis data menggunakan uji statisitik chi-square.

\section{HASIL DAN PEMBAHASAN}

Penelitian ini mendapatkan responden yang menyetujui untuk berpartisipasi dalam penelitian dan telah diseleksi melalui kriteria inklusi dan eksklusi. Terdapat 160 responden yang memenuhi kriteria inklusi tetapi 7 responden tidak dapat dijadikan responden penelitian karena beraktivitas olahraga setiap hari, menggunakan konsol selain smartphone setiap hari dan data yang tidak lengkap sehingga harus dieksklusi dari penelitian sehingga sampel pada penelitian ini berjumlah 153 responden. 
Tabel 1. Karakteristik Responden

\begin{tabular}{|c|c|c|}
\hline Karakterisitik & Frekuensi (n) & Persentase (\%) \\
\hline \multicolumn{3}{|l|}{ Jenis Kelamin } \\
\hline Perempuan & 86 & 56,2 \\
\hline Laki- laki & 67 & 48,3 \\
\hline \multicolumn{3}{|l|}{ Usia } \\
\hline 17 tahun & 1 & 0,7 \\
\hline 18 tahun & 21 & 13,7 \\
\hline 19 tahun & 39 & 25,5 \\
\hline 20 tahun & 59 & 38,6 \\
\hline 21 tahun & 29 & 19,0 \\
\hline 22 tahun & 3 & 2,0 \\
\hline 23 tahun & 1 & 0,7 \\
\hline
\end{tabular}

Durasi Rata-Rata Penggunaan Smartphone

\begin{tabular}{ccc}
$\geq 5$ Jam & 132 & 86,3 \\
$<5$ Jam & 21 & 13,7 \\
Tenosynovitis De & & \\
Quervain & 104 & 68 \\
Positif & 49 & 32 \\
Negatif & & \\
\hline Total & 153 & 100 \\
\hline
\end{tabular}

Dari hasil penelitian ini didapatkan karakteristik responden penelitian berdasarkan jenis kelamin terdiri dari perempuan sebanyak $56,2 \%$ mahasiswa dan laki-laki sebanyak $48,3 \%$ mahasiswa sedangkan berdasarkan usia, dari hasil penelitian ini didapatkan responden yang berusia 17 tahun sebanyak $0,7 \%, 18$ tahun sebanyak $13,7 \%, 19$ tahun sebanyak $25,5 \%, 20$ tahun sebanyak 38,6\%, 21 tahun sebanyak 19\%, 22 tahun sebanyak $2 \%$ dan 23 tahun sebanyak $0,7 \%$. Didapatkan juga responden yang menggunakan smartphone dengan rata- rata perhari $\geq 5$ jam sebanyak $86,3 \%$ mahasiswa, sedangkan responden yang menggunakan smartphone dengan ratarata perhari $<5$ jam sebanyak $13,7 \%$ mahasiswa.

Hal ini sejalan dengan penelitian yang dilakukan oleh Palupi, Sarjana \& Hardianti, yang menemukan lebih banyak pada pengguna smartphone dengan kelompok durasi rata-rata $\geq 4$ jam dibandingkan dengan kelompok yang menggunakan smartphone dengan durasi rata-rata $<4$ jam pada mahasiswa Fakultas Kedokteran Diponegoro. Hal ini dikarenakan sebagian besar mahasiswa 
kedokteran menggunakan smartphone untuk berkomunikasi dan browsing. Selain itu, smartphone juga digunakan sebagai media hiburan oleh mahasiswa untuk menghindari stres (Palupi, Sarjana, \& Hadianti, 2018).

Penelitian ini menemukan responden yang memiliki hasil TDQ positif sebanyak $68 \%$, sedangkan responden yang memiliki hasil TDQ negatif sebanyak $32 \%$. Penelitian ini hampir serupa dengan penelitian yang dilakukan kepada 300 mahasiswa kedokteran di Universitas Ziauddin, Pakistan yang mendapakan setengah dari mahasiswanya memiliki hasil TDQ positif (Ali, Asim, Danish, Ahmad, Iqbal,
\& Hassan, 2014). Namun, hal ini tidak sejalan dengan dengan penelitian yang dilakukan oleh Taufiq, Batool, \& Bashir. Pada mahasiswa kedokteran Allama Iqbal ditemukan lebih banyak pada responden yang memiliki hasil TDQ negatif dibandingkan dengan responden yang memiliki hasil TDQ positif. Perbedaan hasil ini karena pada penelitian Taufiq, Batool, \& Bashir tidak spesifik pada aktivitas tertentu, sedangkan penelitian yang telah dilakukan oleh penulis spesifik pada aktivitas yang menjadi salah satu risiko terjadinya TDQ, yakni aktivitas penggunaan smartphone.

Tabel 2. Hubungan Durasi Rata-Rata Penggunaan Smartphone dengan Kejadian TDQ.

\begin{tabular}{|c|c|c|c|c|c|c|}
\hline Durasi Rata-Rata & \multicolumn{2}{|c|}{ TDQ } & \multicolumn{2}{|c|}{ Total } & Rasio & Nilai \\
\hline Smartphone & Positif & Negatif & (n) & $(\%)$ & $95 \% \mathrm{Cl}$ & \\
\hline$\geq 5$ Jam & $100(75,8 \%)$ & 32 & 132 & 100 & 3,977 & 0,000 \\
\hline$<5$ Jam & $4(19 \%)$ & $\begin{array}{c}(24,2 \%) \\
17(81 \%)\end{array}$ & 21 & 100 & $(1,638-9,656)$ & \\
\hline
\end{tabular}

Tabel 2, menunjukkan hasil uji statistik didapatkan nilai $p$ sebesar $0,000 \quad(p \leq 0,05)$ sehingga dapat disimpulkan bahwa ada hubungan yang siginifikan antara durasi rata-rata penggunaan smartphone dengan kejadian TDQ. Risiko terjadinya TDQ pada pengguna smartphone dengan durasi rata-rata penggunaan $\geq 5$ jam lebih mungkin TDQ sebesar 3,977 dibandingkan pengguna smartphone dengan durasi rata-rata penggunaan $<5$ jam. $\quad(P R=3,977 ; \quad 95 \%$ Confidence Interval 1,638-9,656).

Penelitian ini sejalan dengan penelitian yang dilakukan oleh Ali et al. Penelitian tersebut mendapatkan hasil yang bermakna antara penggunaan smartphone dengan kejadian TDQ pada populasi mahasiswa fisioterapi di Karachi, Pakistan. Hal ini diakibatkan oleh penggunaan smartphone yang sering dan dalam durasi waktu yang lama. Semakin lama durasi penggunaan 
smartphone maka akan menyebabkan pergerakan pada ibu jari yang lebih banyak terutama pada penggunaan smartphone cenderung melakukan pergerakan yang repetitif (Kim \& Kim, 2015).

Gangguan muskuloskeletal pada pengguna smartphone dapat diakibatkan oleh menegangnya otot yang terjadi dalam durasi yang panjang. Penegangan otot tersebut dapat menyebabkan terjadinya stres mekanis pada tendon yang bisa berdampak pada ligamen dan saraf disekitar sendi. Hal inilah yang mengakibatkan manifestasi nyeri pada penderita. Penggunaan smartphone dapat menyebabkan dampak secara fisik apabila digunakan berlebihan terutama dengan durasi lebih dari 5 jam (Kim \& Kim, 2015; Nurratri, et al., 2018)

\section{SIMPULAN}

Berdasarkan hasil penelitian, maka dapat ditarik kesimpulan ;

1) $86,3 \%$ mahasiswa Fakultas Kedokteran Universitas Mulawarman memakai smartphone dengan durasi ratarata perhari $\geq 5$ jam.

2) $68 \%$ mahasiswa Fakultas Kedokteran Universitas Mulawarman mengalami TDQ.

3) Terdapat hubungan antara durasi rata-rata penggunaan smartphone dengan kejadian TDQ.

\section{DAFTAR PUSTAKA}

Akkaya, N., Dogu, B., Unlu, Z., Carli, A.
Gerakan yang repetitif menimbulkan pergesekan, penekanan dan iskemia di sekitar sendi carpometacarpal I. Kondisi ini dapat menyebabkan inflamasi pembungkus tendon sehingga menimbulkan nyeri pada M. abduktor pollicis longus dan M. ekstensor pollicis brevis (Yusuf \& Wulandari, 2013). Selain nyeri dapat juga ditemukan manifestasi klinis pembengkakan dan penurunan rentang gerak sendi. Beberapa penelitian terakhir menemukan adanya penebalan tendon ibu jari pada individu yang sering mengirim pesan singkat dengan menggunakan ponsel namun sejauh ini belum ada data dan penelitian yang membuktikan hal tersebut berdasarkan hasil evaluasi Ultrasonografi (Akkaya, et al., 2015).

B., Akkaya, S., Tekin, L., et al. (2015, June). Ultrasonographic Evaluation of the Flexor Policis Longus Tendon in Frequent Mobile Phone Texters. American Journal Physical Medicine \& Rehabilitation, 94 No.6, 444-448.

Ali, M., Asim, M., Danish, S. H., Ahmad, F., lqbal, A., \& Hassan, S. D. (2014). Frequency of De Quervain's Tenosynovitis and Its Association With SMS Texting. Muscles, Ligaments, and Tendons Journal, 74-78.

Asosiasi Penyelenggara Jasa Internet Indonesia. (2016). Buletin APJII. Jakarta: Asosiasi Penyelenggara Jasa Internet Indonesia. 
Helmi, Z. N. (2015). Buku Ajar Gangguan Muskuloskeletal. (A. Susila, Ed.) Jakarta, DKI Jakarta, Indonesia: Salemba Medika.

Hingarajia, D., Patel, D., Desai, H., \& Dora, V. (2018, March). Prevalence of De Quervain's Tenosynovitis and Its Effect on Pinch Strenght in Mobile Users. International Journal of Recent Scientific Research, 9(3), 2503225035.

International Data Corporation. (2018, August). Smartphone OS Market Share. Retrieved April 14, 2019, from IDC Web Site: https://www.idc.com/promo/smart phone-market-share

Kemenkominfo RI. (2015). Indonesia Raksasa Teknologi Digital Asia. Jakarta: Kemenkominfo RI.

Kim, H.-J., \& Kim, J.-S. (2015, October

1). The Relationship Between Smartphone Use and Subjective Musculoskeletal Symptoms and University Students. Journal Physical Therapy Science, 27, 575-579.

Kulkarni, G., \& Babhulkar, S. (2016). Textbook of Orthopaedics and Trauma (3 ed., Vol. 4). (P. P. Kotwal, \& V. Shankar, Eds.) India: Jaypee Brothers.

Lee, S. (2016, November 14). Quantifying the Benefits of Smartphone Adoption: Digital Device Substitution and Digital Consumption Expansion. Sosial Science Reaserch Network Electronic Journal, 1-55.
Manumpil, B., Ismanto, Y., \& Onibala, F. (2015, April). Hubungan Penggunaan Gadget Dengan Tingkat Prestasi Siswa di SMA Negreri 9 Manado. E Journal Keperawatan, 3 No.2.

Nisa, Z. u., Umer , B., \& Hassan, T. u. (2016). Prevalence of De Quervain's Syndrome Among Young Mobile Phone Users. Journal of Riphah College of Rehabilitation Sciences, 22-24.

Nurmalasari, \& Wulandari, D. (2018, February 2). Pengaruh Penggunaan Gadget Terhadap Tingkat Prestasi Siswa SMPN Satu Atap Pakisjaya Karawang. Jurnal IImu Pengetahuan dan Teknologi Komputer, 3, 25274864.

Nurratri, A. K., Widodo, A., Oklandary , D., Saraswati, E. V., Sukmawati, L., Purnamasari, N. D., et al. (2018). Upaya Preventif dan Edukatif De Quervain's Syndrome pada Pengguna Smartphone di Kalangan Remaja. Jurnal URECOL, 493499.

Oktario, A. (2017). Hubungan antara Intensitas Penggunaan Smartphone dan Motivasi Berprestasi Mahasiswa. Yogyakarta: Fakultas Psikologi Universitas Sanata Dharma.

Palupi, D. A., Sarjana, W., \& Hadianti, T. (2018). Hubungan Ketergantungan Smartphone Terhadap Kecemasan pada Mahasiswa Fakultas Kedokteran 
Diponegoro. Jurnal Kedokteran Diponegoro, 140-145.

Sehar, B., Ashraf, I., Rasool, S., \& Raza, A. (2018, April 15). Frequency of Thumb Pain Among Mobile Phone User Students. Journal of Sheikh Zayed Medical College, Vol.9 No.2, 1406-1408.

Sjamsuhidajat, R., \& de Jong, W. (2017). Buku Ajar IImu Bedah (4 ed., Vol. 1). Jakarta: EGC.

Taufiq, F., Batool, T., \& Bashir, S. (2015). Prevalence of De-Quervain's Tenosynovitis among Medical Students of Allama Iqbal Medical College. Journal of Riphah College of Rehabilitation Sciences, 95-98.

Widhiyanto, A., Munawir, A., \& Prayitno, H. (2017, November). The Effect of Duration of Smartphone Usage on Neck Pain. Dama International Journal of Researchers, 2(11), 54-61.

Yacob, Z., Shah, N. K., Yusof, N. M., Anas, N., \& Zulkipli, S. N. (2017, July). A Proposed Study of Modern Gadgets and Their Influence on Malaysian Adolescents. 6-9.

Yusuf, H., \& Wulandari, I. D. (2013). Penatalaksanaan Fisioterapi Pada De Quervain Syndrome Menggunakan Ultrasound,Tens, dan Terapi Latihan di RSUD Kraton Kabupaten Pekalongan. Jurnal IImu Pengetahuan dan Teknologi, 25 no 1, 51-61. 